\title{
Correcting Bias in Perceptions of Public Opinion Among American Elected Officials: Results from Two Field Experiments *
}

\author{
Joshua L. Kalla ${ }^{\dagger} \quad$ Ethan Porter:
}

October 15, 2019

\begin{abstract}
While concerns about the public's receptivity to factual information are widespread, much less attention has been paid to the factual receptivity, or lack thereof, of elected officials. Recent survey research has made clear that U.S. legislators and legislative staff systematically misperceive their constituents' opinions on salient public policies. We report results from two field experiments designed to correct misperceptions of sitting U.S. legislators. The legislators $(n=2,346)$ were invited to access a dashboard of constituent opinion generated using the 2016 Cooperative Congressional Election Study. Despite extensive outreach efforts, only 11\% accessed the information in Study 1 and only 2.3\% did so in Study 2. More troubling for democratic norms, legislators who accessed constituent opinion data were no more accurate at perceiving their constituents' opinions. Our findings underscore the challenges confronting efforts to improve the accuracy of elected officials' perceptions and suggest that elected officials may resist factual information.
\end{abstract}

${ }^{*}$ We thank Daniel Butler, Peter Aronow, Avi Feller, Donald Green, Kim Gross, Steven Klein, Gabe Lenz, Winston Lin, Eric Schickler, Jasjeet Sekhon, John Sides, and Lynn Vavreck for helpful feedback. Mark McKibbin and participants in UC Berkeley's Undergraduate Research Apprentice Program provided invaluable research assistance in contacting state legislators. We also thank Frank Chi and Will Donahoe for website design. All remaining errors are our own. This research was approved by the George Washington University Committee for Protection of Human Subjects (IRB\#071742). Full replication materials and pre-analysis plans are available in the supplementary materials. The data, replication instructions, and the data's codebook can be found at https://doi.org/10.7910/DVN/0A1AM3.

${ }^{\dagger}$ Assistant Professor, Department of Political Science and Department of Statistics and Data Science, Yale University. josh.kalla@yale.edu, https://joshuakalla.com.

\#Assistant Professor, School of Media and Public Affairs, George Washington University. evporter @ gwu . edu http://www.ethanporter.com 
Concerns about the public's receptivity to factually accurate political information are widespread (Grinberg et al.2019; Lazer et al.|2018; Guess, Nagler and Tucker|2019; Iyengar and Massey|2019; Pennycook and Rand 2019; Berinsky 2017; Porter and Wood 2019). However, little is known about whether elected officials are receptive to factual information and update their views upon learning new information, with some notable exceptions (e.g., Nyhan and Reifler 2014; Butler and Nickerson 2011). This is unfortunate. Many theories of representative democracy depend on politicians having accurate information about what their constituents believe (e.g., Mansbridge 2003). Regardless of whether legislators should behave as "delegates" who mirror the public's will or "trustees" who make use of their own judgment, constituent preferences are often assumed to play some role in informing legislative outcomes (Burke 1986, Pitkin 1967). Yet recent research in the U.S. has made clear that legislators (Broockman and Skovron 2018) and their staffers (Hertel-Fernandez, Mildenberger and Stokes 2019) systematically misperceive constituent opinion, believing that public opinion is significantly more conservative than it actually is. This may be responsible for the rightward shift in American policy in recent decades (Hacker and Pierson 2010).

In this paper, we report the results of two field experiments designed to improve the accuracy of elected officials' perceptions of their constituents' preferences. Relying on data from the 64,600 respondent-2016 Cooperative Congressional Election Study (Ansolabehere and Schaffner 2017), in both experiments we provided sitting U.S. state legislators $(n=2,346)$ the opportunity to view granular information about the policy attitudes of their constituents. Under the auspices of an ad hoc organization we created called District Pulse, legislators were assigned to receive either an invitation to a password-protected website that contained information about the policy preferences of their constituents or, as a placebo, information about those in their broader Census regions, of which there are four nationally. Afterwards, a researcher with no visible ties to District Pulse surveyed the legislators who accessed the information. We anticipated that providing legislators with district-specific information about their constituents' preferences would increase the accuracy 
of their perceptions of those preferences and, potentially, affect their legislative decision-making to better represent those preferences.

Despite the normative and electoral incentives for legislators to learn their constituents' opinions, the vast majority of legislators in our study failed to access the information we provided them about their constituents' preferences. Moreover, the post-treatment surveys make clear that even the legislators who accessed the information about their constituents were unaffected by it. Not only do we find that most legislators in these experiments were uninterested in what their constituents believe-but even those who accessed such information were made no more accurate as a result.

The resistance of legislators to factually accurate political information potentially stands in contrast to the behavior of those they represent. Researchers have shown that in some settings presenting the public with factual information can improve their accuracy about political matters (Gerber and Green 1999; Guess and Coppock|2018; Hill 2017; Kraus, Rucker and Richeson 2017; Wood and Porter 2019). 1. However, across the two field experiments described here, we find that legislators from both parties are unwilling to more accurately perceive their constituents' preferences. They resist becoming more factually accurate about their constituents even though they likely face electoral incentives to do so (Mayhew 1974). Indeed, we fielded one of the experiments in the run up to the 2018 midterm U.S. election, a time when legislators are potentially most incentivized to accurately know their constituents' beliefs. Yet the proximity of the election made legislators in these experiments no more responsive to or interested in accurate information about their constituents' preferences.

\footnotetext{
${ }^{1}$ Future work should directly compare the accuracy of perceptions and responsiveness to corrections of legislators and citizens (e.g., Lee et al. 2019). We do not make such direct comparisons in the present paper.
} 


\section{Experimental Design}

Our evidence comes from pre-registered randomized field experiments we conducted in 2017 and 2018 Both experiments adhered to the same design. They proceeded in five steps. First, using data from the 2016 CCES and multi-level regression and poststrafication (Gelman and Little 1997; Park et al. 2004; Lax and Phillips 2009; Warshaw and Rodden 2012), we estimated district-level public opinion in 2,346 state house and senate districts on eight issues. Specifically, we estimated district-level public opinion about immigration, mandatory minimum sentencing, renewable portfolio standards to increase the production of renewable energy, background checks for gun purchases, the minimum wage, highway funding, abortion, and repealing the Affordable Care Act (full wording of the policy areas is presented in the supplementary materials). Then, we randomly assigned each state legislator to receive access to the public opinion estimates derived from the CCES on a random set of four of the eight issues. Next, we randomly assigned legislators to receive either polling estimates specific to their district or polling estimates covering the four broad U.S. Census regions. The former, which provided legislators with information specific to their own constituents, acted as our treatment of interest; the latter was our placebo. Because Census regions are large, we anticipated that providing the regional polling data about all four regions would be uninformative for a state legislator trying to understand her specific constituent's opinions. (On average, the district-specific and Census region polling estimates differed by 8.1 percentage points across issue items.) Legislators also received no polling information on a random set of issues (four of eight possible issues), thereby providing us a control group.

In order to increase the credibility of the information we provided the legislators, we partnered with Chi/Donahoe, a digital creative consulting firm with expertise in political data visualizations, to create District Pulse. After receiving an invitation, state legislators could log onto District Pulse to access their public opinion polling data. To further ensure this dashboard was taken seriously

\footnotetext{
${ }^{2}$ IRB approval was obtained before conducting the experiments. Full replication materials, pre-analysis plans, data, and code are in the supplementary materials and available at Kalla and Porter (2019).
} 
by state legislators, we pre-tested it with several current and former legislators and staffers. The results of this pre-testing are reported in the supplementary materials. In addition, our invitation noted that the polling data came from a large National Science Foundation-funded study and that the information was not being provided by either a partisan or special interest group. We received no replies from legislators or their staff questioning the credibility or legitimacy of District Pulse.

Figure 1 shows what District Pulse looked like for a state legislator randomly assigned to receive district-specific polling. Had this legislator been randomly assigned to the placebo condition, the web page would have looked identical except that the sentence reading "In your legislative district..." would have been removed, as would have the district-specific data $3^{3}$

We provided access to District Pulse by emailing custom URLs and passwords to legislators. Under the auspices of District Pulse, we sent three rounds of email invitations. We also made one set of phone calls to legislators to remind them to access the information. In all of our communications with legislators, we noted the large sample size of the polling, the National Science Foundation support, and the non-partisan, academic source. The text of the invitation emails and phone calls are included in the supplementary materials. We were able to track which legislators accessed the polling data, when they did so, and how many times, by requiring them to log into District Pulse.

Two weeks after the final invitation to access District Pulse, an unaffiliated academic invited the legislators to complete a survey. For each of the eight policy proposals, we asked three distinct outcome measures: their perception of constituent support, which was our primary outcome of interest, as well as the legislator's personal policy positions and the legislator's expected voting behavior if the policy were to come before them (wording of the outcome measures is included in the Appendix). By comparing responses on these three outcome measures across the treatment, placebo, and control conditions, we can test our hypothesis that providing district-specific polling

\footnotetext{
${ }^{3}$ The treatment did not provide any polling information disaggregated by likely voters, partisans, or other constituent characteristics. Future research should consider how legislators respond to these types of polling results.
} 


\section{OHO PULSE}

\section{State House District 112, Maine}

Below you can find maps on where the American public stands on a number of policy issues using data from the Cooperative Congressional Election Study - a 65,000 person survey funded by the National Science Foundation. If you have any questions about these surveys, please email @districtpulse.us.

\section{Issues}

- Immigration

- Crime

- Environment

- Abortion

\section{Immigration}

In your legislative district (State House District 112, Maine), the data show that $36.3 \%$ support granting legal status to people who were brought to the US illegally as children, but who have graduated from a U.S. high school.

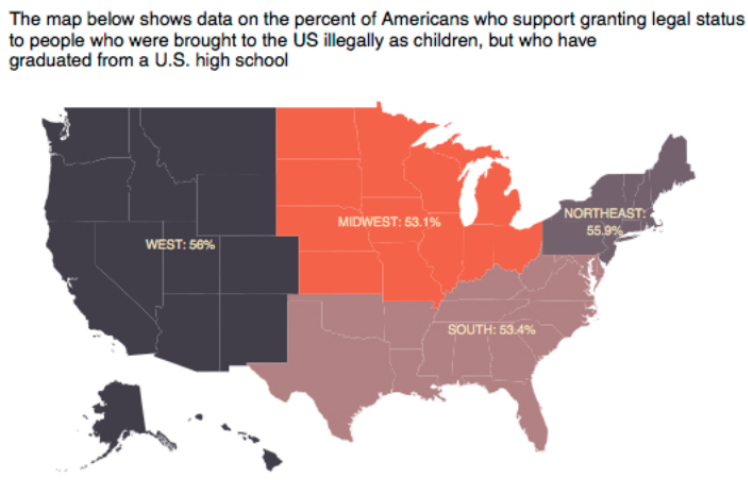

Figure 1: Sample District-Specific Polling Treatment. Note: In placebo, the web page would have looked identical except that the sentence reading "In your..." would have been removed, as would have the district-specific data. 
information to legislators about their constituents' preferences should increase the accuracy of their perceptions and, potentially, their expected legislative behavior.

Following the procedure for analyzing field experiments with survey outcomes (Broockman, Kalla and Sekhon 2017), we then analyzed the data by limiting the post-treatment survey responses to the compliers - those legislators who logged in to access District Pulse ( $n=300$ across both studies). $14 \%$ of compliers responded to the post-treatment survey and answered our primary outcome measure ( $n=43$ across both studies). This response rate is comparable to the rates found in recent surveys of political elites (Broockman and Skovron 2018; Broockman et al. 2017; Teele, Kalla and Rosenbluth 2018). A full $85 \%$ of responders to our survey identified themselves as legislators. As we note in the supplementary materials, these responders are broadly representative in terms of baseline constituent opinion on the eight issues, Trump vote share, and median household income. Furthermore, there is no evidence of differential attrition on who responded to these surveys.

Our primary outcome was examining whether providing district-specific information reduces the prevalence with which elected officials misperceive their constituents' preferences (Broockman and Skovron 2018; Hertel-Fernandez, Mildenberger and Stokes 2019). Following our pre-analysis plan, we coded misperceptions as the absolute value of the legislator's response to a survey question asking what percentage of constituents they believe support each policy area minus the district support estimated using the CCES data; this was the information directly conveyed to the treatment group. We tested our other two pre-registered outcomes with survey questions on legislators' policy preferences for each of the eight policy areas and questions regarding intended voting behavior. That is, we asked legislators their level of agreement with each policy and how they would vote if each policy came before them. (Full question wordings are in the supplementary materials). We then generated a "long" dataset where each row is a legislator-issue (meaning each legislator who was a complier and responded to the post-treatment survey appears eight times) and columns are the three outcome measures. We analyzed the data by regressing each dependent variable on the treatment indicator using OLS and calculating cluster-robust standard errors at the state legislator 
level. In accordance with our pre-ananlysis plan, our primary model includes pre-treatment covariates for the legislator's party, whether the legislator serves in an upper or lower chamber, Trump's 2016 vote share in the district, and state fixed effects. $4^{4}$

We took several steps to maximize statistical power. First, by randomly assigning each legislator to receive polling information on four of eight issues but collecting outcome measures for all eight, we were able to conduct a within-subjects analysis and increase the effective sample size (see Green, Wilke and Cooper (2017) for a similar design). Second, by randomly assigning subjects to receive either district-specific or placebo regional polling aggregates and tracking whether a legislator accessed their polling information, we were able to create a placebo group to estimate the treatment-on-treated (TOT) effect that is robust to our low compliance rate (Nickerson 2005 ; Broockman, Kalla and Sekhon 2017). With these design features and the observed compliance and post-treatment survey response rates, our experiment had $80 \%$ power to detect a 7 percentage point reduction in misperceptions from an average of 18 percentage points in control. The supplementary materials includes many additional details on the MRP procedure, the placebo, balance checks, implementation, and robustness checks under alternative model specifications.

The first experiment was conducted in the fall of 2017. The second experiment was conducted in the fall of 2018, in advance of the 2018 U.S. election. Prior researchers have found that elites have responded to informational treatments when such treatments allude to their reelection chances (Nyhan and Reifler 2014). In 2018, we took the legislators who had not accessed District Pulse in 2017, randomly assigning 917 such legislators to receive the same email invitation as used in the original study, and another 917 legislators to receive an electoral-salience invitation. The latter invitation noted in the subject line that legislators could "Access detailed polling before the elections" and referred to the elections in the main body (see the supplementary material for the full emails).

\footnotetext{
${ }^{4}$ Note that contrary to our pre-analysis plan, no baseline survey was conducted, so no baseline responses are included as covariates. Results are the same with and without covariates (see SM Tables 11-13.)
} 


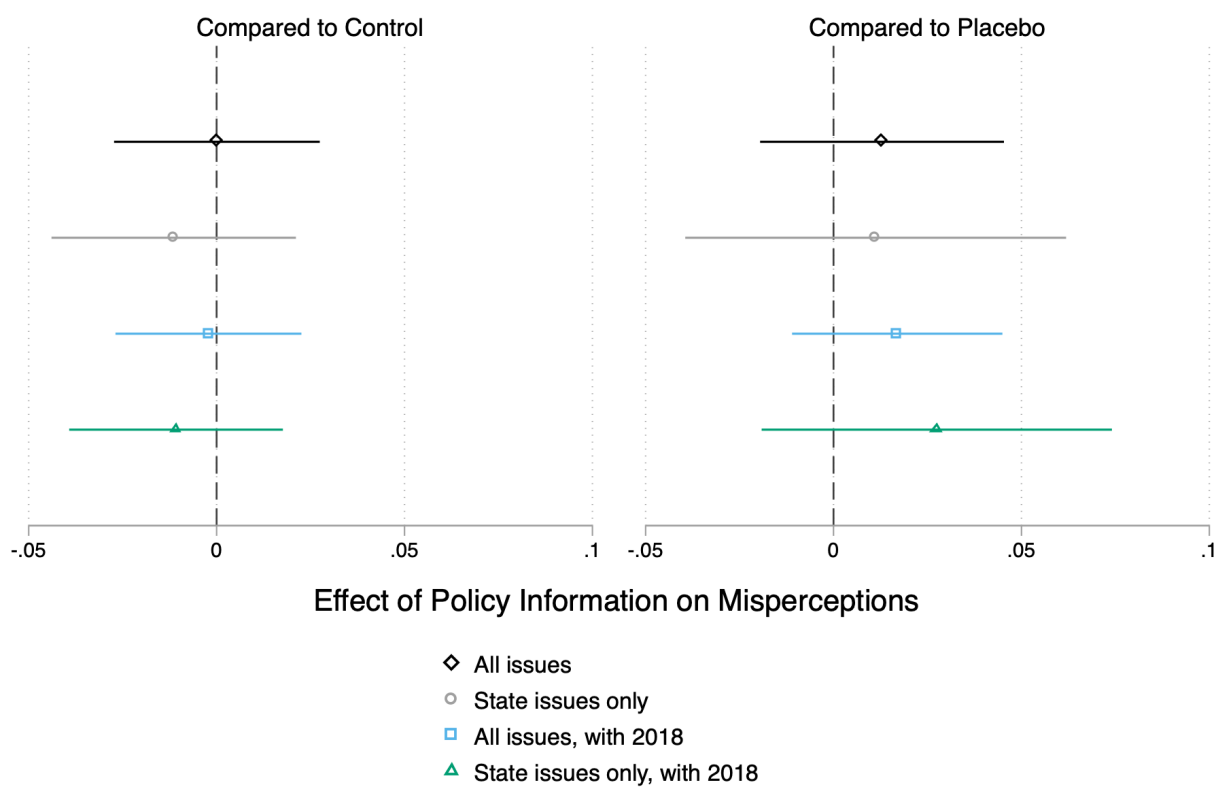

Figure 2: Treatment Effect on Misperceptions. Note: Higher values indicate greater misperceptions. All models include pre-treatment covariates and state fixed effects that were specified in our pre-analysis plan. Lines denote the 95\% confidence intervals clustering at the state legislator level. 312 legislator-responses (39 legislators) are included in the 2017 data and 31 legislator-responses (4 legislators) from 2018.

\section{Results}

Despite administering a statistically well-powered experiment in which we offered state legislators a credible source of information about their specific constituents' preferences, we were unable to improve the accuracy of legislators' perceptions. Legislators in the control group who received no polling information whatsoever misperceived their constituents' policy preferences by 18 percentage points on average, similar to previous estimates (Broockman and Skovron 2018; HertelFernandez, Mildenberger and Stokes 2019). Legislators provided with the placebo regional polling information and treatment district-specific information misperceived constituent policy preferences by 16 and 18 percentage points, respectively. In sum, legislators remained roughly equivalently uninformed about their constituents' preferences regardless of whether they were provided with information about their specific constituents; whether they received information about the four U.S. Census regions; or whether they received no information at all. 
Figure 2 presents the main results. In this figure, we regress the outcome of misperception on a treatment indicator and covariates for the legislator's party, whether the legislator serves in an upper or lower chamber, Trump's 2016 vote share in the district, and state fixed effects and calculate cluster-robust standard errors at the state legislator level, since each observation in this regression is a legislator-issue (all pre-specified in our pre-analysis plan). In the left-hand panel, we limit our analysis to observations randomly assigned to receive district specific polling on that issue or no polling on that issue (control). In the right-hand panel, we limit our analysis to those observations receiving either the district-specific polling or the Census region polling (placebo). Each panel then includes four treatment effect estimates: (1) using all policy issues and limited to our 2017 study (sample size is 20 legislators and 80 legislator-responses in treatment, 39 and 156 in control, and 19 and 76 in placebo5); (2) using only those policy domains (mandatory minimum sentences, renewable portfolio mandates, gun purchase background, infrastructure spending, and banning abortions) over which state legislators have direct legislative authority and limited to our 2017 study (20 legislators and 50 legislator-responses in treatment, 39 and 102 in control, and 19 and 43 in placebo); (3) using all issues and including both the 2017 and 2018 studies (22 legislators and 88 legislator-responses in treatment, 43 and 171 in control, and 21 and 84 in placebo); and (4) using just the state-level issues and both the 2017 and 2018 studies (22 legislators and 55 legislatorresponses in treatment, 43 and 110 in control, and 21 and 50 in placebo). ${ }_{6}^{6}$

Figure 2 demonstrates that district-specific polling has no effect on reducing legislators' misperceptions when compared to either the control or the placebo. In fact, compared to placebo, the sign is pointing in the opposite direction than expected. The results are robust when examining only those policy domains over which state legislators have direct legislative authority and when including the 2018 replication. As an additional robustness test, we examine the accuracy

\footnotetext{
${ }^{5}$ Recall that the same legislator receives polling information (whether Census or district-specific) on four issues and no polling information on four issues. Hence, the same legislator appears twice in these counts. A total of 39 and 4 legislators completed the 2017 and 2018 experiments, respectively.

${ }^{6}$ Two diagrams in the supplementary materials illustrate the design and sample size at each stage.
} 
of the legislators who recalled receiving the polling information from District Pulse, as measured at the end of the post-treatment survey. Despite any bias potentially introduced by conditioning on this post-treatment variable (Montgomery, Nyhan and Torres 2018), among this group, we continue to find no treatment effects. Legislators who received the treatment information misperceived public opinion on average by 17 percentage points compared to 16 and 17 percentage points for the placebo and control groups, respectively. Even among the subset of the treatment group that recalled receiving polling information from District Pulse, their degree of inaccuracy remains substantively large and no more accurate than the placebo and control groups. In the supplementary materials, we present additional robustness results and interaction effects with electoral safety, which consistently fail to find evidence of either statistically or substantively significant effects as a result of providing polling information to legislators. However, given our limited sample size, these interaction effects may be underpowered. Turning to the other outcomes, we again fail to find an effect of providing polling information on legislators' policy preferences and their voting intentions. The same robustness checks described above for misperceptions were also applied to these two outcomes; the results remain unchanged. Complete results are presented in the supplementary materials.

\section{Discussion}

Our results are sobering. While previous research (Broockman and Skovron 2018; Hertel-Fernandez, Mildenberger and Stokes 2019) has established that elected officials systematically misperceive what their constituents want, the evidence presented here portrays such officials as immune to our non-partisan efforts to correct those misperceptions, possibly opening the door to influence from others, such as likely voters, co-partisans, political activists, lobbyists, or donors (Barber 2016, Butler and Dynes 2016; Miler 2010; Kalla and Broockman 2016; Leighley and Oser 2018). In our experiments, legislators did not update their attitudes to match their constituents' on salient 
political issues, even when the requisite information was quite literally at their fingertips.

We can think of three potential explanations for our results. First, legislators may not have received or trusted the information provided to them. Had the polling come to legislators via alternative channels or sources (e.g., Butler and Nickerson 2011), it may have had a greater impact, suggesting the need for further replication. Our results, while stark, are limited to these particular legislators and this particular intervention; other interventions tested on other samples may result in different findings. Second, legislators may discount aggregate measures of their constituents' attitudes, and instead focus on the preferences of political elites, lobbyists, donors, co-partisans, and other policy-demanders whom they view as more central to their electoral prospects (Bawn et al. 2012; Barber 2016; Miler 2010, Gilens 2012). Knowing what the average constituent believes on policy matters may be less important to elected officials than knowing what these others believe. Third, given increasing levels of polarization in statehouses (Shor and McCarty|2011) and the "nationalization" of U.S. politics (Hopkins 2018), legislators may think of themselves not as delegates for their specific constituents, but as participants in national partisan debates. Knowing what their constituents believe on policy matters may be less important than knowing the positions of their national party - and sticking to them.

Our experiment expands upon an innovative prior experiment by Butler and Nickerson (2011). During a 2008 New Mexico special legislative session, the authors sent 35 state legislators polling from their districts on support for a one-time tax rebate during a special legislative session. They find in this particular circumstance that legislators receiving their district-specific polling were much more likely to vote with their constituents than the control group. Since that research was conducted, American political elites and state legislators have become increasingly polarized (Shor and McCarty 2011). Our results may differ from those of Butler and Nickerson (2011) because the current study included a more diverse set of contentious political issues across a much broader swath of legislators at a time of heightened polarization. Other differences between the settings of the studies, such as the fact that Butler and Nickerson (2011) provided polling information directly 
tied to an upcoming legislative vote and in conjunction with a local media source, may also explain why the legislators in Butler and Nickerson (2011) were more responsive to constituent opinion than the legislators studied here. Our results underscore the importance of replication in the social sciences, especially as the external political world changes.

Our two experiments reported here should not be the last word on this topic of constituency influence in American politics. Though we have shown that improving the accuracy of legislators' perceptions of constituent preferences is difficult, that does not mean it is impossible. A different treatment might have yielded different results. And even though we went to great lengths to maximize our statistical power, a design with even greater power might have been able to detect smaller effects. In addition, we could not control who accessed District Pulse and who took the posttreatment survey; it may have been the case that there were systemic differences between those who took the survey and those who did not, thereby preventing us from observing effects. Finally, it is possible that the set of legislators willing to respond to a survey are somehow different and less treatment responsive than the majority of legislators who chose not to respond. These limitations are especially important given how our result diverge from some prior work (Butler and Nickerson 2011). With all this in mind, future research should investigate ways to spur legislators to have more accurate impressions of what their constituents believe, and to update their own impressions and attitudes accordingly.

\section{References}

Ansolabehere, Stephen and Brian Schaffner. 2017. “CCES Common Content, 2016.” http: //dx.doi.org/10.7910/DVN/GDF6Z0,

Barber, Michael J. 2016. "Representing the Preferences of Donors, Partisans, and Voters in the US Senate.” Public Opinion Quarterly 80(S1):225-249. 
Bawn, Kathleen, Martin Cohen, David Karol, Seth Masket, Hans Noel and John Zaller. 2012. "A theory of political parties: Groups, policy demands and nominations in American politics." Perspectives on Politics 10(3):571-597.

Berinsky, Adam. 2017. "Rumors and Health Care Reform: Experiments in Political Misinformation.” British Journal of Political Science 47(2):241-262.

Broockman, David E and Christopher Skovron. 2018. "Bias in perceptions of public opinion among political elites." American Political Science Review 112(3):542-563.

Broockman, David, Joshua Kalla and Jasjeet S Sekhon. 2017. "The design of field experiments with survey outcomes: A framework for selecting more efficient, robust, and ethical designs." Political Analysis 25(4):435-464.

Broockman, David et al. 2017. Having Their Cake and Eating It, Too:(Why) Local Party Leaders Prefer Nominating Extreme Candidates. Technical report Working paper, Stanford University.

Burke, Edmund. 1986. "Speech to the Electors of Bristol." http://press-pubs. uchicago.edu/founders/documents/v1ch13s7.html.

Butler, Daniel and David Nickerson. 2011. "Can learning constituency opinion affect how legislators vote? Results from a field experiment." Quarterly Journal of Political Science 6(1):55-83.

Butler, Daniel M and Adam M Dynes. 2016. "How Politicians Discount the Opinions of Constituents with Whom They Disagree.” American Journal of Political Science 60(4):975-989.

Gelman, Andrew and Thomas Little. 1997. "Poststratification into many categories using hierarchical logistic regression." Survey Methodology 23(2):127-135.

Gerber, Alan and Donald Green. 1999. "Misperceptions about perceptual bias." Annual Review of Political Science 2(1):189-210. 
Gilens, Martin. 2012. Affluence and influence: Economic inequality and political power in America. Princeton University Press.

Green, Donald, Anna Wilke and Jasper Cooper. 2017. Reducing Intimate Partner Violence through Informal Social Control: A mass media experiment in rural Uganda. Technical report Columbia University.

Grinberg, Nir, Kenneth Joseph, Lisa Friedland, Briony Swire-Thompson and David Lazer. 2019. "Fake news on Twitter during the 2016 U.S. presidential election." Science 363(6425):374-378.

Guess, Andrew and Alexander Coppock. 2018. "Does counter-attitudinal information cause backlash? Results from three large survey experiments.” British Journal of Political Science pp. 1-19.

Guess, Andrew, Jonathan Nagler and Joshua Tucker. 2019. "Less than you think: Prevalence and predictors of fake news dissemination on Facebook." Science Advances 5(1).

Hacker, Jacob S and Paul Pierson. 2010. Winner-take-all politics: How Washington made the rich richer-and turned its back on the middle class. Simon and Schuster.

Hertel-Fernandez, Alexander, Matto Mildenberger and Leah C Stokes. 2019. "Legislative staff and representation in Congress." American Political Science Review 113(1):1-18.

Hill, Seth J. 2017. "Learning Together Slowly: Bayesian Learning about Political Facts." The Journal of Politics 79(4):1403-1418.

Hopkins, Daniel. 2018. The Increasingly United States: How and Why American Political Behavior Nationalized. University of Chicago Press.

Iyengar, Shanto and Douglas S Massey. 2019. "Scientific communication in a post-truth society." Proceedings of the National Academy of Sciences 116(16):7656-7661. 
Kalla, Joshua and Ethan Porter. 2019. "Replication Data for: Correcting Bias in Perceptions of Public Opinion Among American Elected Officials: Results from Two Field Experiments.”. URL: https://doi.org/10.7910/DVN/OA1AM3

Kalla, Joshua L and David E Broockman. 2016. "Campaign contributions facilitate access to congressional officials: A randomized field experiment.” American Journal of Political Science 60(3):545-558.

Kraus, Michael W, Julian M Rucker and Jennifer A Richeson. 2017. “Americans misperceive racial economic equality." Proceedings of the National Academy of Sciences 114(39):10324-10331.

Lax, Jeffrey and Justin Phillips. 2009. "How should we estimate public opinion in the states?" American Journal of Political Science 53(1):107-121.

Lazer, David M. J., Matthew A. Baum, Yochai Benkler, Adam J. Berinsky, Kelly M. Greenhill, Filippo Menczer, Miriam J. Metzger, Brendan Nyhan, Gordon Pennycook, David Rothschild, Michael Schudson, Steven A. Sloman, Cass R. Sunstein, Emily A. Thorson, Duncan J. Watts and Jonathan L. Zittrain. 2018. “The science of fake news.” Science 359(6380):1094-1096.

Lee, Nathan, Brendan Nyhan, Jason Reifler and D.J. Flynn. 2019. More Accurate Yet More Polarized? Comparing the Factual Beliefs of Government Officials and the Public. Technical report Working paper, Stanford University.

Leighley, Jan E and Jennifer Oser. 2018. "Representation in an era of political and economic inequality: How and when citizen engagement matters." Perspectives on Politics 16(2):328344.

Mansbridge, Jane. 2003. "Rethinking representation." American political science review 97(4):515-528.

Mayhew, David R. 1974. Congress: The electoral connection. Yale University Press. 
Miler, Kristina. 2010. Constituency representation in Congress: the view from Capitol Hill. Cambridge University Press.

Montgomery, Jacob M, Brendan Nyhan and Michelle Torres. 2018. "How conditioning on posttreatment variables can ruin your experiment and what to do about it." American Journal of Political Science 62(3):760-775.

Nickerson, David. 2005. "Scalable protocols offer efficient design for field experiments." Political Analysis 13(3):233-252.

Nyhan, Brendan and Jason Reifler. 2014. "The Effect of Fact-Checking on Elites: A Field Experiment on U.S. State Legislators." American Journal of Political Science 59(3):628-640.

Park, David et al. 2004. "Bayesian multilevel estimation with poststratification: state-level estimates from national polls.” Political Analysis 12(4):375-385.

Pennycook, Gordon and David G Rand. 2019. "Fighting misinformation on social media using crowdsourced judgments of news source quality." Proceedings of the National Academy of Sciences 116(7):2521-2526.

Pitkin, Hanna F. 1967. The concept of representation. Univ of California Press.

Porter, Ethan and Thomas J. Wood. 2019. False Alarm: The Truth About Political Mistruths in the Trump Era. Cambridge University Press.

Shor, Boris and Nolan McCarty. 2011. "The Ideological Mapping of American Legislatures." American Political Science Review 105(3):530-551.

Teele, Dawn Langan, Joshua Kalla and Frances Rosenbluth. 2018. "The Ties That Double Bind: Social Roles and Women's Underrepresentation in Politics.” American Political Science Review 112(3):525-541. 
Warshaw, Christopher and Jonathan Rodden. 2012. "How should we measure district-level public opinion on individual issues?" The Journal of Politics 74(1):203-219.

Wood, Thomas and Ethan Porter. 2019. “The elusive backfire effect: Mass attitudes' steadfast factual adherence." Political Behavior 41(1):135-163. 